XII Congreso de Ingeniería de Organización

$2^{\text {nd }}$ International Conference on Industrial Engineering and Industrial Management

Burgos, $3-5$ de septiembre de 2008

\title{
Structure and relationships within global manufacturing virtual networks
}

\section{Estructura y relaciones en las redes virtuales de fabricación global}

\author{
Carlos Rodríguez Monroy' and José Ramón Vilana Arto² \\ ' Departamento de Ingeniería de Organización, Administración de Empresas y Estadística. Escuela Técnica Superior de \\ Ingenieros Industriales. Universidad Politécnica de Madrid. Doctor ingeniero industrial.crmonroy@etsii,upm.es \\ 2 Ingeniero industrial.joseramon.vilana@bystronic.com
}

Fecha de recepción: 06-10-08

Fecha de aceptación: 02-12-08

\begin{abstract}
Global Manufacturing Virtual Networks (GMVNs) are dynamically changing organizations formed by Original Equipment Manufacturers (OEMs), Contract Manufacturers (CMs), turn-key and component suppliers, R+D centres and distributors. These networks establish a new type of vertical and horizontal relations between independent companies or even competitors where it is not needed to maintain internal manufacturing resources but to manage and share the network resources. The fluid relations that exist within the GMVNs allow them a very permeable organization easy to connect and disconnect from one to each other as well as to choose a set of partners with specific attributes. The result is a highly flexible system characterized by low barriers to entry and exit, geographic flexibility, low costs, rapid technological diffusion, high diversification through contract manufacturers and exceptional economies of scale. Anyhow, there are three major drawbacks in the GMVNs that should be considered at the beginning of this type of collaborations: I) the risk of contract manufacturers to develop their own end-products in competition with their customers; 2) the technology transfer between competitors OEMs through other members of the GMVN and 3) the lose of process expertise by the OEMs the more they outsource manufacturing processes to the network.
\end{abstract}

Key words: global manufacturing virtual network, supply chain, contract manufacturing.

Resumen. Las Redes Virtuales de Fabricación Global (RVFG) son organizaciones dinámicas en continuo cambio formadas por fabricantes (OEMs), fabricantes subcontratados (contract manufacturers), proveedores de componentes y llave en mano, centros de I+D y distribuidores. Estas redes establecen relaciones de tipo horizontal y vertical entre empresas independientes o incluso competidores donde no es necesario mantener internamente grandes recursos fabriles sino gestionar y compartir eficientemente los recursos de la red. Las relaciones fluidas que existen en las RVFG les permiten alcanzar una organización muy permeable fácil de conectarse y desconectarse así como colaborar simultáneamente con un grupo variado de participantes con diferentes atributos. El resultado es un sistema altamente flexible caracterizado por bajas barreras de entrada y salida, flexibilidad geográfica, bajos costes, difusión tecnológica en la red muy rápida, alta diversificación a través de los fabricantes subcontratados y excepcionales economías de escala. De todos modos existen tres grandes inconvenientes en estas redes que deberían ser considerados al comienzo de este tipo de colaboraciones: I) el riesgo de los fabricantes subcontratados de desarrollar sus propios productos compitiendo con los OEMs, 2) la transferencia tecnológica entre OEMs competidores a través de otros miembros de la red y 3) la perdida de control y experiencia en procesos fabriles por parte de los OEMs a medida que «desverticalizan» su cadena de valor a otros miembros de la red.

Palabras clave: redes virtuales de fabricación global, cadena de suministro, fabricación subcontratada.

\section{Introducción}

The global environment, in which companies presently operate, with ever more globalized markets, consolidations of companies or strategic alliances, is forcing firms into finding new ways of collaboration that would improve the integration and synchronization of the different functions and stages of the value chain of their products. Today, many traditional OEMs have deverticalized a large part of their value chain by contracting out much of their manufacturing processes to turnkey suppliers or contract manufac- 
turers. In many industries, it is starting to be usual to collaborate among production centres and even manufacturing networks in an attempt to provide a more efficient response to the most demanding needs of the market and obtain competitive advantages in an ever more globalized environment. In some industries such as aeronautics (Shi et al., 2005), electronics (Shi and Gregory, 2003) or the automotive industry (Sturgeon, 1999), there is even talk of global manufacturing virtual networks (GMVN), based on a new model of manufacturing architecture with a high potential for development in order to satisfy an ever more demanding and fragmented market (Li et al., 2000). The formation of GMVNs obeys four strategic approaches: I) Excellence of their operations, 2) Access to new markets: geographical, of product, client segments and offset strategies, 3) Diversification of financial risks or 4) Access to new technologies.

Within these networks the suppliers maintain close relations with a very varied number of clients permitting them to achieve better economies of scale and also minimizing the risk of losing a specific collaboration with one of them. On the other hand, the OEMs maintain relations with an interchangeable group of suppliers according to different technical and geographical particularities. GMVNs minimize the almost exclusive interdependence between the OEM and the suppliers which existed in the first phases of disintegration of the value chains (Fine,
1998). The result is a network with a very permeable and flexible structure, with very fluent relations and very low entrance and exit barriers, permitting a very rapid difussion of technology and very high economies of scale. A GMVN is made up of many different value chains which interact among each other sharing one or several components of these chains. While the value chain of a company defines the vertical sequence of sequential activities permitting a particular product or service to be produced, a GMVN consists of several value chains (one for each actor participating in the network) including relations of the vertical and horizontal type and which are continually and dynamically being reconfigured (Sturgeon, 2000). In this context, a value chain could be considered as a sub-unit of a GMVN, more static and determined than the latter, though much easier to represent and define.

\section{Basic aspects of the GMVN}

In order to study this new phenomenon of collaboration among production centres and to understand in greater detail the nature of global manufacturing virtual networks, all the factors influencing the design of a global manufacturing virtual network will be considered.

Figure I proposes a basic diagram for analysing GMVNs and which is made up of four basic vectors

Figure I

Basic aspects of the GMVNs

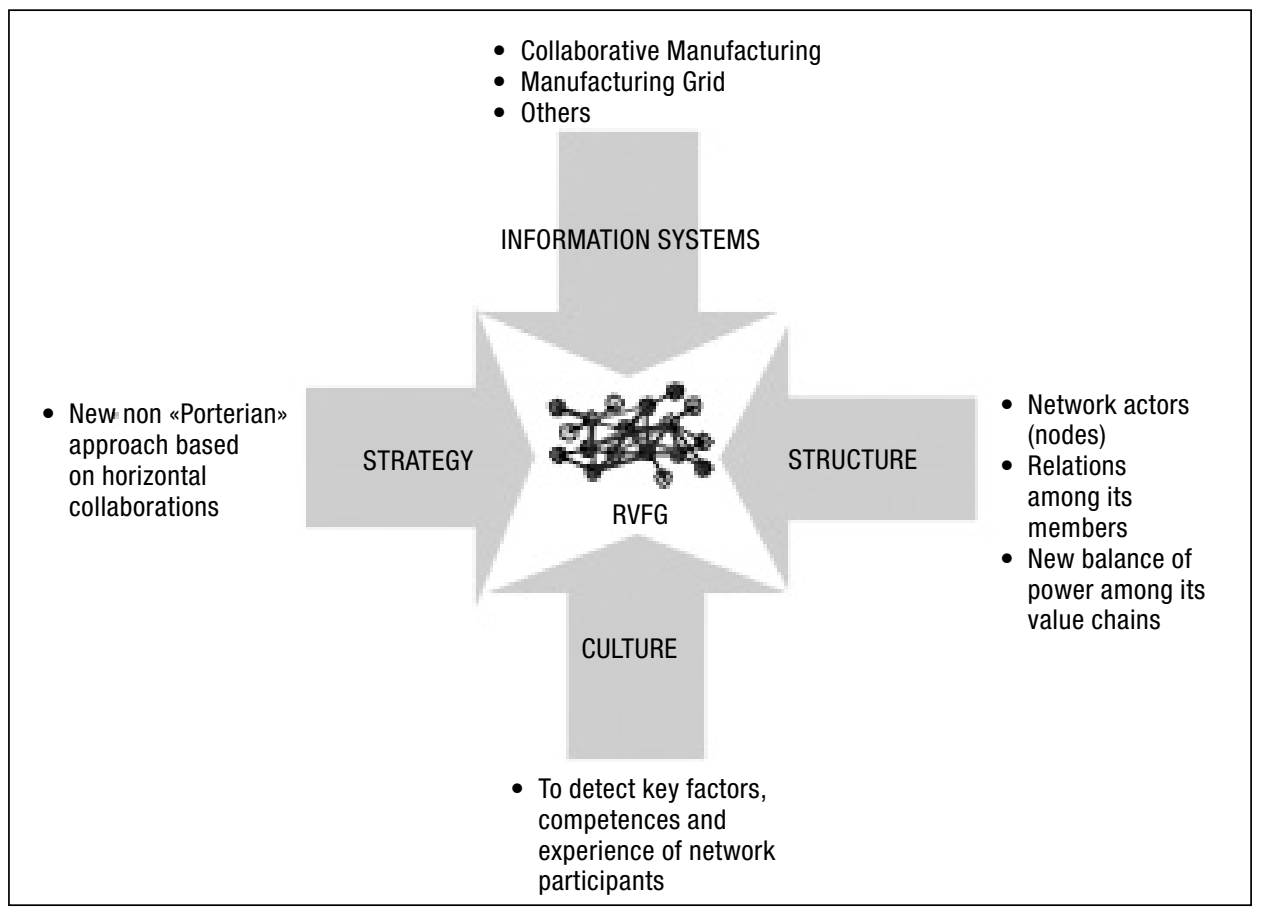


encompassing all the relevant aspects of GMVNs: their strategy, their structure, their information systems and their culture. The structure of the network includes the definition of the main actors making it up (the nodes of the network), as well as the type of relations and collaborations that are established among its members. Moreover, these structures must not just be regarded as something static and rigid but instead as a system undergoing a continual process of change permeable to outside factors. As it will be seen below, the role of the OEM, the contract manufacturer or the distributor in the network and their relations with other members of the network is something very diffuse and variable.

The strategy of GMVNs is another aspect to bear in mind. In a globalized environment with vertical and horizontal collaborations among their members, even with competitors, one can consider the validity of a classical Porterian strategy (Porter, 1996). The manufacture of some aeronautical motors involves the participation of the great majority of manufacturers (competitors) on the market, as in the case of the GP 7200 which powers the new Airbus 380 whose manufacture is being done by an alliance between General Electric and Pratt \& Whitney with collaborations from MTU Aero Engines, Snecma, and Tech Space Aero. This paradox is permitted by the OEMs because the benefits obtained through this collaboration are much greater than the inherent risks of collaborative manufacturing. The plant which Flextronics has in Mexico permits it to produce special electronic devices (television connectors to the internet) for Philips at very low cost because this same device is simultaneously being made for Sony on an adjacent line. This same contract manufacturer, Flextronics, bought a factory off Ericsson with a longlife agreement though just a third of its production capacity was dedicated to its products while a greater proportion is for one of its greatest competitors: Motorola. This collaboration Flextronics - Motorola was permitted by Ericsson since it enabled it to achieve very much greater economies of scale. The close collaborations between competitor OEMs in the same sector are very frequent in GMVNs. This factor, combined with horizontal collaborations with other sectors due to related diversification thanks to the contract manufacture of technological patents in different areas (Arruñada, 2006) means that the strategy of GMVNs follows patterns different from the two-dimensional «Porterian» approach based on the search for a balance of forces in the sector and on achieving a competitive advantage that is sustainable in time.
The third relevant aspect of GMVNs is the information system which the network has. Many authors have studied this field such as the work by Li et al. (2004) on manufacturing grids or jiao et al. (2006) on collaborative manufacturing. These studies analyse how to coordinate the utilization of design and manufacturing resources that are heterogeneous, independent and distributed throughout the network. In the new development of the model 787 Boeing a new concept of virtual design and manufacture has been implemented known as Global Collaborative Environment formed by a platform on the Internet which links up all the participants, internal and external, in the project, independently of their location, and permits them to jointly design and virtually simulate not just the functioning of the parts independently but also the entire process of structural sub-units of the plane. Nevertheless, the degree of virtualization of these networks will be inversely proportional to the intensity of formal and informal information flows in them. For this reason, a final relevant aspect of GMVNs is their culture. Analysing how to overcome the fear inherent to collaborating with companies outside of one's organization, in some cases competitors is one of the challenges of GMVNs.

This article will explore into the structures of GMVNs. It will describe its different actors, the type of relation among them and how the actual dynamic of the GMVN and the sometimes diffuse and permeable nature of them is continually provoking new balances of forces.

\section{Structure of the GMVN: size, location and «virtualization» level}

In the design of the GMVNs it is fundamental to bear in mind the aspects relating to the actual manufacturing centres forming the nodes of the network and the relations among them. There are three important characteristics to consider in terms of the manufacturing centres of these organizations: their size, location and degree of specialization (Hayes and Wheelwright, 1984). Traditionally, the size of a factory is related to the desired capacity and economies of scale that can be obtained.

Another relevant aspect which defines the networks is the location of their nodes. Many studies have been made on the determining factors when it comes to choosing the optimum location for a facility. In a vertically integrated GMVN (when the large majority of manufacturing centres belong to the same company) 
the criteria are different since account will have to be taken of the possible interdependence among its nodes, the flow of input-output materials, the sequence of its value chain, the closeness of the nodes to certain markets or raw materials or corporate synergies at the network level. Arntzen et al. (1995) analysed how Digital Equipment Corporation (DEC) redesigned its network including the relocation of some of its nodes at a corporate level. Other study by Ferdows (1997) analyse the strategic decisions in a manufacturing network of several companies and determined that the most influential factors were access to low production costs, qualified labour and proximity to strategic markets. This last factor was also defined by Vereecke and Van Dierdonck (1999) as the most important when it comes to defining the location of the manufacturing centres of a manufacturing network.

In any case, when talking about GMVNs, the criteria of location of the different nodes of the network are more difficult to define when speaking about the different independent organizations making up this type of network. In these cases, no location criteria can be defined and the only way of defining or changing a particular location is by collaborating with another independent organization, otherwise the location has to be taken as a fact. For that reason, in GMVNs the geographical location of the manufacturing centres making up the network cannot be determined or designed previously since they are outside the control of the network. The important thing would be the relations established between the different nodes and whether a particular location is desired according to the criterion described above: access to new markets, qualified labour or lower production costs, the solution would entail incorporating new nodes into the network that comply with some of these requisites. In the same manner, in a GMVN, the traditional interpretation of the optimum size applicable to the network is inadequate since no account is taken of the size of the actual nodes and it makes no sense to speak of economies of scale or desired capacity that belongs to the traditional design of a manufacturing centre. When speaking about the size of a GMVN aspects will be taken into account such as the relations between the different nodes of the network and the number of organizations which the network encompasses.

An important factor when it comes to modelling a GMVN is to analyse the degree of «virtualization» of it. It is understood that the virtual component of the network is related to the intensity of the collaborations with companies external to the organization itself (Li et al., 200 I). Obviously, the relations among the nodes of the network will be largely determined by whether or not one belongs to any organization of the network and the flows of information, materials or synchronization of the different nods will depend on the type of organization on which they depend in the network. Therefore, a first classification of GMVNs will be in line with the degree of virtualization of the network. Figure 2 shows a simplified version of this classification.

The simplest configuration is the production centre formed by a single company and a single centre. This would be a traditional production plant without any external relations with other manufacturing centres in the value chain of the product. The Global Manufacturing Network (GMN) would be formed by a just one company and several dependent manufacturing centres constituting a network with strong relations among its nodes which can specialize in terms of product or process, following different strategic criteria of the company: geographical, access to markets, closeness to suppliers, economic or highly

Figure 2

Virtualization level of the GMVNs

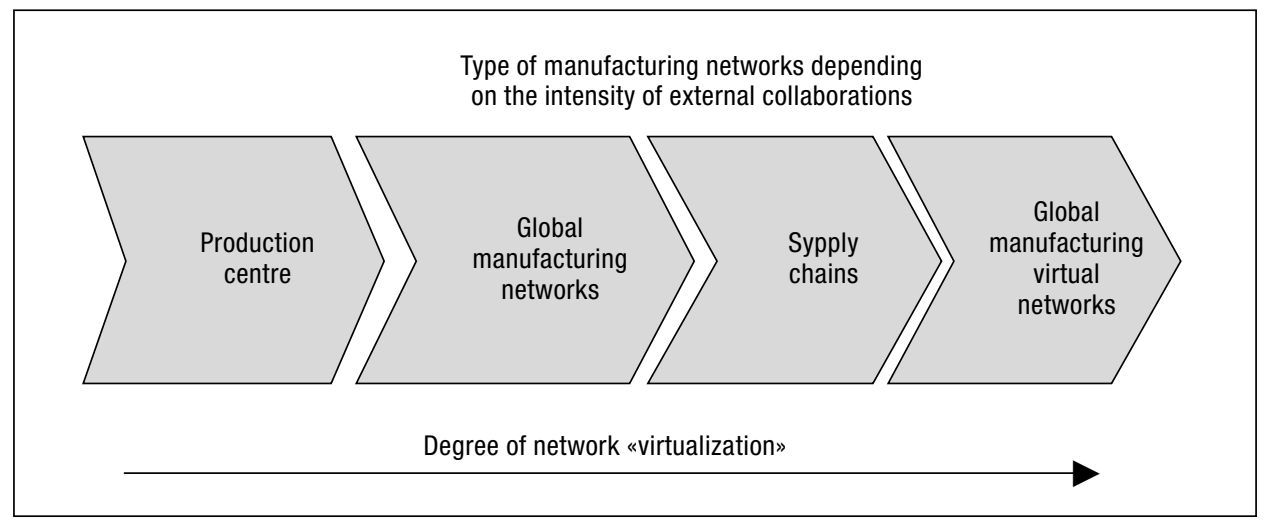

Dirección y Organización, Núm. 37, Febrero 2009 | ISSN: I|32-I75X 
qualified labour, and which overall determine the global productive capacities of the company. In this type of network, vertical integrations play a major role and there exist many examples such as Acer (Mathews, 1998), or DEC (Arntzen, 1995). What are known as Supply Chains are shaped by several companies in which each one contributes one or a few production centres. Finally, Global Manufacturing Virtual Networks are more complex structures formed by several companies and several production centres (Li et al., 2000). In this type of network the location of the different centres of a company will be a decision taken at the independent corporate level but which will take into account the location of other centres of independent companies in the network.

Continuing with the classification of Figure 2, in the Production Centres and GMNs the important thing would be the actual nodes of the network and where aspects related to the optimization of the manufacturing centres would have more importance, as if one were dealing with a «black box», an endogamous model based on the internal efficiency of the production process. In the Supply Chain, on the other hand, the important thing would be the relations among the nodes of the network taking into account the synergies that could be achieved with other production centres or the added value that could be offered to customers. Finally, GMVNs will take both approaches into account due to the nature of the elements of the network set up by several independent companies with several plants or production centres per company.

In GMVNs, their members can choose a specific supply chain of the network depending on the type of product or service desired. In this way, they can vary their strategy from the flexibility given by the virtual organizations in order to obtain new business opportunities or enter into new markets or continue to use their own manufacturing centres in innovative products with a high risk of undesired technology or intellectual transfer.

\section{Actors in GMVNs}

A fundamental aspect in the definition of the GMVNs is the classification of the various actors making up the network, in other words, the nodes of the structure whose value chains interact among each other at some point.

The low operational efficiency of one of the main actors, the integrated enterprise, has meant that many of them have undertaken a rapid vertical disintegration of their value chain (e.g.: Ford, IBM) and doubts have also been raised over this category of company in numerous studies (Fine, 1998). The OEM (Original Equipment Manufacturer) is another of the main actors of the network, though nowadays this term is not a very homogenous concept, since it is also used by old manufacturers who have completely disintegrated their value chain and have contracted out a large part of their manufacturing process to outside companies retaining just the design of the product and the marketing. Dell or IBM are a good example of this practice (Sturgeon, 1999, 2000).

The contract manufacturer is one of the actors of GMVNs that have forcefully appeared in recent years, especially in various industrial sectors such as electronics, the automotive industry and aeronautics. Contract manufacturing is a production model consisting of the complete contracting out of a manufacturing process by the OEM to companies specializing in manufacture. In some case it implies that the original manufacturer does not have any physical contact with the product that it has designed and will later market (Arrunada, 2006). This practice started in 1981 when IBM decided to outsource part of the manufacture of its personal computers and nowadays firms such as Lenovo or Sanmina manufacture and assemble complete computers with a wide variety of known brands of OEMs.

A final relevant participant in the network are the research centres, consisting of universities, technology centres, or any outside company capable of supplying patents, licences, intellectual property rights, technological solutions directly related to the products or services supplied. This type of collaboration is very frequent in products with a high technological value such as in the aeronautics industry. The manufacturer of Rolls Royce aeronautical motors maintains collaborations with over 40 outside $R \& D$ centres known as UTCs (University Technology Centres), such as the collaboration which they maintain with Oxford University in the development of computational fluid dynamics and heat transfer. This type of collaboration constitutes one of the most important strategic relations of GMVNs.

\section{The new role of GMVNs played by contract manufacturers}

The appearance of contract manufacturers in the manufacturing networks has considerably increased competition in some sectors since they facilitate the 
appearance of new companies which were unable to overcome the entrance barriers previously produced by the heavy capital investment or economies of scale that were necessary in order to produce certain products. The main advantage for OEMs is the reduction in fixed labour costs, reduction in unit costs per product, disinvestment in productive assets permitting an appreciable improvement in the return on investment, and an increase in productivity and flexibility due to labour reduction, permitting them to focus on their main fields such as R\&D or marketing.

Figure 3 summarizes the different roles which the contract manufacturer can play within GMVNs and their relation to OEMs. Depending on each option chosen by the contract manufacturer, a different balance of forces will be formed in the GMVN. Option (I) is the most classical one where an OEM contracts out a large part of its manufacturing processes to a contract manufacturer, as in the case of Valmet, a contract manufacturer which carries out the final assembly of all Boxter models of Porsche. As this company advances in its learning curve its costs become more and more reduced and it gains access to the know-how that it can use in the development of its own products. For that reason, as indi- cated in point (2), a natural tendency of the contract manufacturer will be to manufacture its own products including the creation of its own brand, thus becoming an OEM.

One way of selling these new products is through the distributors channels in the network (using the own brand of the new OEM) as indicated in point (3). Lenovo (a manufacturer of personal computers) is a good example of this conversion of contract manufacturer into OEM, using its own distribution channels and those existing in the network it has become the leader in its sector. Another variant of this tendency is to use the brand of a distributor as indicated in the figure (4). The major distribution chains such as Wal Mart or Carrefour can demand to large contract manufacturers to manufacture under their own distribution brand products of the same quality as the major brands but at appreciably lower prices. This is the case of Solectron, the old contract manufacturer of IBM which was later on contracted by the distributor Ingram Micro to manufacture personal computers under its own brand. This process is going to be seen more and more with other products where this has so far seemed unthinkable, such as automobiles or domestic appliances.

Figure 3

Different relations of the contract manufactures in GMVNs

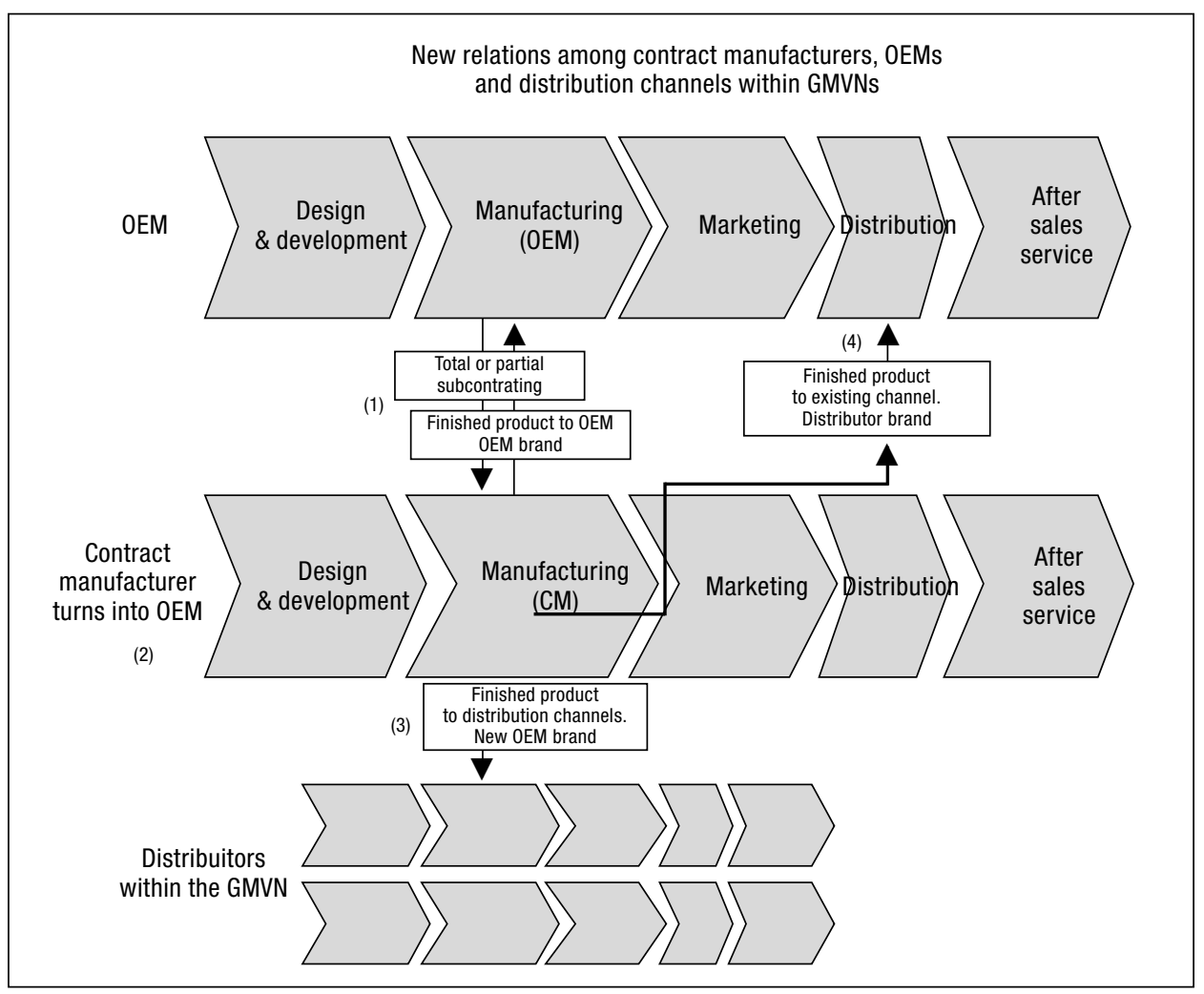




\section{New relations of forces in GMVNs}

OEMs traditionally maintain a patent portfolio much larger than the production activities they carry out (Brusoni et al., 200l). It is not unusual for an automobile manufacturer, for example, to hold patents in the field of fuel cells, ceramic coatings or batteries, which lie outside of its main market but which are related to its internal development in order to achieve technological advances in certain components (Arruñada, 2006). GMVNs permit these OEMs to undergo a related diversification via the contract manufacturers which exploit the potential of these patents at a very low cost and risk. In this way, companies like Dell have been able to go beyond their roots in the PC market and enter into the market of consumer electronics with plasma and LCD televisions or DVD players as a result of patents that were developed internally.

Relations between the different nodes of GMVNs are normally of the multipoint type (several to several) since when these relations are based on exclusivity the OEMs find themselves limited, on the one hand, of the economies of scale which the contract manufacturer could achieve with products from the competition. On the other hand, they are isolated from other innovative proposals coming from other contract manufacturers. For that reason, OEMs that depend exclusively on one or a few contract manufacturers in order to protect their intellectual property are going to find it difficult to offer the market products that are competitive in cost and quality. So, the strategy of OEMs of entering into alliances with contract manufacturers in the network has to be based on very intense and close relations with contract manufacturers but at the same time favouring those which establish relations with other OEMs.

Contract manufacture in GMVNs will on the one hand cause the OEMs to reduce their own manufacturing resources as far as possible, restricting themselves solely to the manufacture of prototypes or innovative products which they do not wish to contract out at the production capacity existing in the network, and thereby be able to devote themselves to their main fields such as design or marketing. On the other hand contract manufacturers are going to be the major suppliers of the network specializing solely in manufacturing. They are also going to have to increase the flexibility of the facilities in order to be able to serve a large number of OEMs. The entrance barriers of GMVNs are going to be appreciably reduced permitting the entrance of new OEMs which were previously unable to meet the heavy investment in manufacturing resources or achieve certain economies of scale. Another tendency is going to be the diversification of OEMs due to finding an outlet for the patent portfolios they possess or which they can acquire on the market. Finally, the changes in production strategy and location is also gong to be significant. There is no doubt that there is going to be a new balance of forces in the network. On the one hand the distributors will be competing with products similar to those of the OEM in terms of quality at very much lower prices. And on the other, the OEMs will be changing their production strategy in the network seeking to differentiate themselves with new marketing strategies, accessing new geographical markets or diversifying into other sectors.

Of course, there are limitations and risks in the GMVN model, the greatest of them possibly being the change of role which the most successful suppliers and contract manufacturers in the network can carry out. The ever increasing dependence of OEMs on a series of suppliers that are advancing more and more in their learning curve, improving their technical and operational ability and strengthening their financial positioning, can lead them to wanting to design their own products and compete with their customers. Another risk is undesired technology transfer between rival OEMs on the network via the suppliers and the contract manufacturers. For this reason, the OEMs should never contract out the main fields of the company. Sony Ericsson only contracts out the manufacture of products that are mature and have therefore already been copied in the market, while Cisco internally retains the manufacture of the latest generation of routers.

\section{Production capacity in GMVNs}

The ease of establishing relations with several suppliers and customers in GMVNs and changing them easily permits a fluency in relations that favours the optimization of the production capacity at the global level of the network against a more restrictive traditional approach with exclusive and rigid relations between an OEM and supplier where it is more difficult to break these contractual relations in the short and medium term. This capacity can be easily available to OEMs that are more successful in the network to the detriment of those losing market share. Likewise, the OEMs will be permitted to trace out global strategies for manufacture at the network level outsourcing the manufacture of more mature products with hardly any differentiation regarding the competition and 
Figure 4

Utilization of the production capacity of GMVNs

\begin{tabular}{|c|c|c|}
\hline \multirow{5}{*}{$\begin{array}{c}\text { High } \\
\text { Number of } \\
\text { manufacturing } \\
\text { processes involved }\end{array}$} & \multicolumn{2}{|c|}{ Utilization of production capacity of GMVNs } \\
\hline & $\begin{array}{c}\text { Contract } \\
\text { manufacturer }\end{array}$ & $\begin{array}{c}\text { OEM } \\
\text { (in-house) }\end{array}$ \\
\hline & $\begin{array}{l}\text { Components } \\
\text { supplier }\end{array}$ & $\begin{array}{l}\text { - Components } \\
\text { supplier } \\
\text { - R+D center } \\
\text { - OEM }\end{array}$ \\
\hline & & High \\
\hline & \multicolumn{2}{|c|}{ Product innovation } \\
\hline
\end{tabular}

therefore with fewer risks of technology transfer, thereby achieving major economies of scale that are beyond the reach of an independent company and retaining the manufacture of more innovative products in-house.

The table of Figure 4 represents all the possibilities of utilization of the manufacturing resources of GMVNs according to the number of processes affected and the degree of innovation of the product or service. If the innovation is low and the number of processes too, then we would be faced with the classical contracting out of a product to a supplier of components or subsystems. If the product continues to be not very innovative but the number of processes involved is high then the contract manufacturer would be the suitable collaborator, in fact some OEMs contract out their entire manufacturing processes to these companies. On the other hand, when the innovation of the product is high it is worth while retaining the manufacture of these products inhouse, particularly if the number of processes affected is high, in order to minimize the risks of transfer of technology and intellectual property. Porsche never contracts out its 911 model which is where it applies its latest developments, instead it is assembled in its Leipzig plant in Germany, on the other hand, its Boxter range, which is less innovative, is indeed contracted out.

\section{Conclusions}

In a GMVN the traditional interpretation of basic concepts in the traditional design of a manufacturing centre, such as its size, location or optimum capacity, is inadequate. The important thing is how the relations are established among the different nodes and if it is wished to optimize one of these factors or criteria such as access to new markets, qualified labour, incorporating new products or services or lower production costs, then the solution is going to incorporate new nodes into the network that comply with some of these requisites.

GMVNs are very permeable and strongly deverticalized structures which permit a very varied group of suppliers and OEMs to establish relations very easily in line with a wide variety of technical, economic and geographical specifications. The result is a tremendously flexible system characterized by very fluent relations with low entrance and exit barriers, low costs, a rapid spread of technology in the network and high economies of scale. The production capacity of the network can migrate towards the most successful OEMs as against those that are losing market, achieving a very intensive utilization of the production capacity at the network level.

Diversification is also going to be one of the most important effects of this type of organization, due mainly to the growing importance of the contract manufacturers. The OEMs can use the resources of the network to develop the patent portfolios they possess, making use of the manufacturing resources of the contract manufacturers and using the distribution channels of GMVNs. On the other hand, GMVNs allow the OEMs to create production strategies at the global level internally retaining the production capacity of the most innovative products and outsourcing to the network the production needs of the most commoditized products. In any case there are three major risks which have to be considered when establishing this type of collaboration I) the risk of cannibalization of the role of OEMs by contract manufacturers which develop their own products in competition with their customers as they gain experience in manufacturing processes 2 ) technology transfer among rival OEMs on the network via the contract manufacturers and 3 ) the loss of control and experience in manufacturing processes outsourced by the OEMs.

\section{References}

ARNTZEN, B.C.; BROWN, G.; HARRISON, .T.P., y TRAFTON, L.L, ( 1995). «Global supply chain management at Digital Equipment Corporation». Interfaces, 25 (I), pp. 69-93.

ARRUÑADA, B., y VÁZQUEZ, X. (2006). «When your contract manufacturer becomes your competitor». Harvard Business Review (September).

BRUSONI, S.; PRENCIPE, A., y PAVITT, K. (200I). «Knowledge specialization, organization coupling, and the 
boundaries of the firm: why do firms know more than they make?». Administrative Science Quarterly, 46 (4), pp. 597-621.

FERDOWS, K. (1997). Making the most of foreign factories. Harvard Business Review, 75 (2), pp. 73-88.

FINE, C. (1998). Clockspeed - winning industry control in the age of temporary; advantage. New York: Perseus Books.

HAYES, R.H., y WHEELWRIGHT, S.C. ( 1 984). Restoring our competitive edge: competing through manufacturing. New York: Wiley.

JIAO JIANXIN, R.; XIAO YOU, y ARUN KUMAR (2006). «An agent-based framework for collaborative negotiation in the global manufacturing supply chain network Robotics and Computer-Integrated». Manufacturing, 22, pp. 239-255.

LI R.; YUT., y FANG M. (2004). The reliability management of manufacturing grid, CIMS and robot center. FAIM2004, Toronto, Canada.

LI, X.; SHI,Y., y GREGORY, M.J. (2000). Global manufacturing virtual network (GMVN) and its position in the spectrum of strategic alliance. EurOMA $7^{\text {th }}$ International Annual Conference, Ghent, Belgium, pp. 330-337.

MATHEWS, J.A., y SNOW, C.S. (1998). «A conversation with the Acer Group's Stan Shih on global strategy and management». Organizational Dynamics, 27(I), pp. 65-74.
PORTER, M. ( 1 996). «What issStrategy?». Harvard Business Review, Noviembre-diciembre 1996.

RUDBERG, M., y OLHAGERB, J. (2003). «Manufacturing networks and supply chains: and operations strategy perspective». OMEGA, octubre, pp. 29-39.

SHI,Y., y GREGORY, M. (2003). «From Original equipment manufacturers to total solution providers: an emergence of global manufacturing virtual network in electronics industry». International Journal of Service Technology and Management, 4 (4-6), pp. 33 I-346.

SHI,Y.; FLEET, D., y GREGORY, M. (2005). Global manufacturing virtual network and its position in manufacturing systems. The $7^{\text {th }}$ Annual International Manufacturing Symposium, Institute for Manufacturing, Dept. of Engineering, University of Cambridge

STURGEON, T., y FLORIDA, R. ( 1999). Globalization and Jobs in the aautomotive industry. Center for Technology Policy, and Industrial Development, Massachusetts Institute of Technology, Cambridge.

STURGEON,T.J. (2000). How do we define value chains and production networks? MIT IPC Working Paper 00-0 I I, BeIlagio Value Chains Workshop, September 25 - October I, 2000; Rockefeller Conference Center, Bellagio, Italy

VEREECKE, A., y VAN DIERDONCK, R. (1999). Design and management of international plant networks: research report. Gent: Academia Press. 